\title{
Magnitude and Trends of Childhood Cancer in India
}

\author{
Satya Prakash Yadav \\ Pediatric Hematology Oncology and Bone Marrow Transplant Unit, Cancer Institute, Medanta The Medicity Hospital, Gurgaon, \\ Haryana,122001.satya_1026@hotmail.com
}

I ndia is a big country with a young population. Children and adolescents are nearly $40 \%$ of the population. Cancer in children and adolescents is highly curable. But barriers to cure remain in a country like India and first hurdle is diagnosing all children with cancer [1]. Reasons for no diagnosis or delayed diagnosis and referral are $-a$ ) insufficient political priority and funding from government, $b$ ) incorrect diagnosis and risk stratification, $c$ ) lack of diagnostic labs and centres for pediatric oncology, $d$ ) lack of trained manpower and training courses in pediatric oncology, and e) socio-economic and cultural factors [1]. New cases of childhood cancer in India have been quoted to be around 50,000 annually but on what basis this number was reached in not known. Is this number right? In this issue, Arora, et al. [2]. give us a fresh perspective and new numbers of around 52,366 annually, much higher than from previously predicted number of 28,712 annually. If we include adolescents also then annual number is expected to reach 76,805 [2]. There is a huge gap $(>50 \%)$ in perceived or agreed number and previously predicted number, leading to suggestions that childhood cancer diagnosis is being missed. Reaching the unreached is the new mantra to improve outcomes of childhood cancer. Lack of integrated national health service and referral system is the main reason why childhood cancer patients are being missed. Training of primary care doctors and nurses in suspecting cancer is needed and improving diagnostics and reducing cost of tests can improve this.From certain geographical areas of India (mountains, north east, islands, desert etc); its difficult to collect data. More males are diagnosed with childhood cancer than females- a stark finding in India [2]. Gender gap $>10 \%$ is possibly explained by gender bias in the Indian society.

Knowing the full burden of cancer is a must for government to allocate resources. Making cancer a notifiable disease can help in capturing the exact numbers. Few states like Punjab, have already done this [1].There is a need for national cancer registry for the same [3]. Linking all medical colleges and post graduate training institutes and cancer centers in a national grid/registry can help collect this data. Cancers like leukemia, which are easier to diagnose by simple blood tests or bone marrow tests, are picked up more easily and brain tumors are either not diagnosed or diagnosed late because it needs imaging like CT scan or MRI, which are not easily available [2]. However, progress has been made on all fronts in the last few decades to improve outcomes of childhood cancer in India, especially acute lymphoblastic leukemia [4].

To know the trends of childhood cancer we need longterm data. Delhi is big city and quite representative of India with mixed rural and urban population. In this issue, Malhotra, et al. [5] describe patterns and trends of childhood cancer in Delhi. Over 25 years, on an average 500 cases/year were diagnosed, which is in agreement with numbers predicted by Arora, et al. [2] for Delhi. Childhood cancer has increased by nearly $100 \%$ over these last 25 years in Delhi [5]. Pesticides and pollution may have a link and studies are needed to prove it. Does religion have connection? Does diet have an impact? Does education have an impact? A study reported incidence of cancer in children of different religions is similar to that of proportions of population of different religions in Delhi except for Jain religion where incidence of cancer is 6 times higher despite lesser number children in 0-6 year in this population as compared to other religions. Major difference is the dietary practices, but another reason could be increased literacy levels in Jain community improving chances of better access to care [6]. Data regarding comprehensive childhood cancer burden in country is lacking due to low and urban predominant coverage of population-based cancer registry programs. The childhood cancer services in India are predominantly restricted to few tertiary care centres in major cities [7]. Certain specialized treatments like eye enucleation, radiotherapy or limb salvage surgery are not available at all the centers. This may be the reason for higher reporting of retinoblastoma and bone tumors from Delhi registry [5,7]. In a survey of 20 pediatric cancer units across the country; approximately 3500 childhood cancer cases were diagnosed annually. Top five cancers reported were leukemia-34\%, brain tumors- 
$10 \%$, lymphoma- $10 \%$, bone tumors- $9 \%$ and retinoblastoma-5\% [8]. These findings are similar to Delhi registry [5] but again highlight that brain tumors are underdiagnosed.

To improve the cure of childhood cancer in India; the very first step is establishing a national cancer registry and improving diagnosis and referral of children with cancer. Both professionals and the government need to step up for this onerous task.

Funding: None; Competing interest: None stated.

\section{REFERENCES}

1. Yadav SP, Rastogi N, Kharya G, et al. Barriers to cure for children with cancer in India and strategies to improve outcomes: a report by the Indian Pediatric Hematology Oncology Group. Pediatr Hematol Oncol. 2014;31:217-24.

2. Arora RS, Bagai P, Bhakta N. Estimated national and state level incidence of childhood and adolescent cancer in India. Indian Pediatrics. 2021;58:417-23.

3. Marwaha RK, Kulkarni KP. Childhood acute lymphoblastic leukemia: Need of a national populationbased registry. Indian Pediatr. 2011;48:821.

4. Yadav SP, Ramzan M, Lall M, Sachdeva A. Childhood acute lymphoblastic leukemia outcome in India: Progress on all fronts. J Pediatr Hematol Oncol. 2012;34:324.

5. Malhotra RK, Manoharan N, Nair O, Deo SVS, Bakshi S, Rath GK. Patterns and trends of childhood cancer incidence (0-14 years) in Delhi, India: 1990-2014. Indian Pediatr. 2021;58:430-5.

6. Yadav SP, Sachdeva A. Linking diet, religion and cancer. J Clin Oncol. 2007; 25:18 suppl:21172.

7. Ganguly S, Kinsey S, Bakhshi S. Childhood cancer in India. Cancer Epidemiol. 2021;71(Pt B): 101679.

8. Yadav SP, Sachdeva A, Katewa S, et al. Survey of pediatric oncology services in India. Pediatr Blood Cancer. 2009;53:849 (abstract PP.018). 